\title{
Prenatal US diagnosis of congenital imperforate hymen
}

\author{
Puneet Bhargava $\cdot$ Manjiri Dighe
}

Received: 20 November 2008 /Revised: 3 February 2009 / Accepted: 2 March 2009/Published online: 21 March 2009

(C) Springer-Verlag 2009

A 32-year-old woman, gravida 1 , para 0 , was referred for third-trimester sonography at 34 weeks' gestation to evaluate fetal growth. Sonography revealed a female fetus with an echogenic, midline, nonvascular pelvic mass (Fig. 1, arrow) and no associated genitourinary abnormality. Differential diagnoses included an ovarian mass, distended rectum, hydrocolpos, vaginal atresia and urogenital sinus. Postnatal US revealed an echogenic, fluid-containing midline pelvic mass (Fig. 2, black arrow) in the setting of an imperforate hymen. The cervix is marked (double white arrows). The

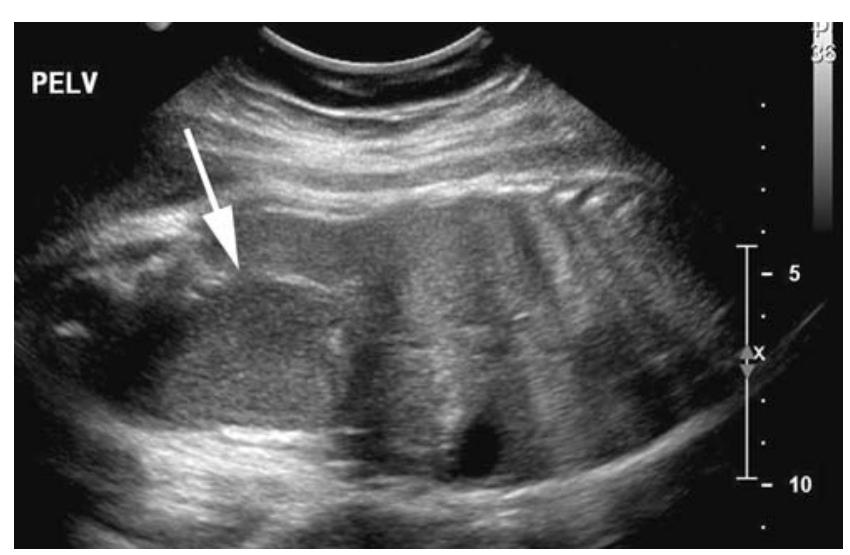

Fig. 1 Prenatal mid-sagittal US image

P. Bhargava $(\bowtie)$

Department of Radiology,

Children's Hospital \& Regional Medical Center,

4800 Sand Point Way NE,

Seattle, WA 98105 , USA

e-mail: bhargp@u.washington.edu

\section{Dighe}

Department of Radiology, University of Washington, Seattle, WA, USA

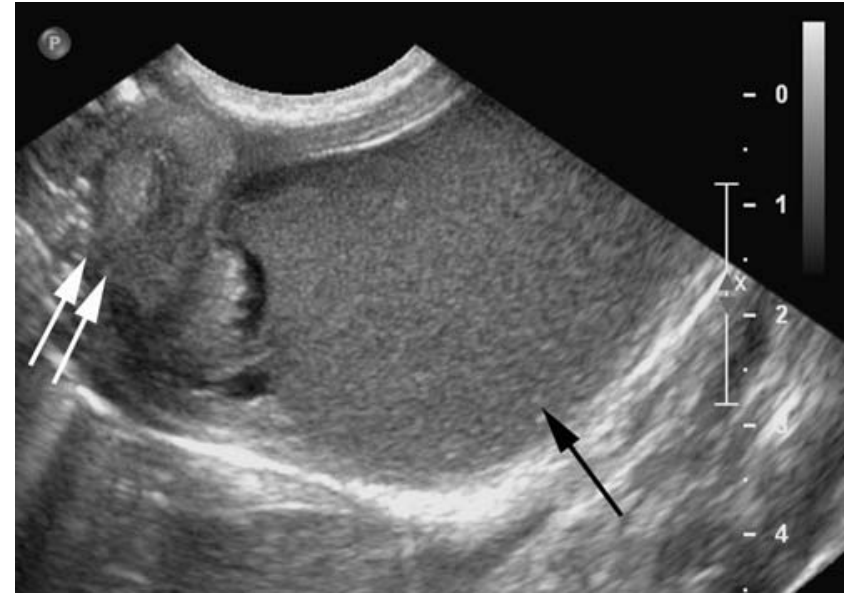

Fig. 2 Postnatal mid-sagittal US image

mass resolved following incision and drainage of clear mucoid fluid. Congenital imperforate hymen usually presents in infancy or early childhood. The diagnosis in the early antenatal period is rare because it seldom causes hydrocolpos or hydrometrocolpos [1]. Sonography is the imaging technique of choice for prenatal diagnosis [2] and evaluation for syndromic disorders (McKusick-Kaufman, Ellis-van Creveld and Bardet-Biedl syndromes), genitourinary anomalies such as persistent urogenital sinus and nephronia, cloacal dysgenesis and urinary tract obstruction.

\section{References}

1. Adaletli I, Ozer H, Kurugoglu S (2007) Congenital imperforate hymen with hydrocolpos diagnosed using prenatal MRI. AJR 189: W23-W25

2. Winderl LM, Silverman RK (1995) Prenatal diagnosis of congenital imperforate hymen. Obstet Gynecol 85:857-860 